\title{
FGF18 Enhances Migration and the Epithelial-Mesenchymal Transition in Breast Cancer by Regulating Akt/GSK3ß/B- Catenin Signaling
}

\author{
Na Song ${ }^{a}$ Jiateng Zhong ${ }^{a, b}$ Qing Hu ${ }^{a}$ Tengteng Gua Bo Yang ${ }^{c}$ \\ Jinghang Zhang ${ }^{b}$ Jian Yu ${ }^{b}$ Xiaoyan Ma ${ }^{a}$ Qiuyue Chen ${ }^{a}$ Jinbo Qja Yanlong Liu ${ }^{d}$ \\ Wei Su ${ }^{b}$ Zhiwei Feng ${ }^{a, e} \quad$ Xianwei Wang ${ }^{a}$ Haijun Wang ${ }^{a, b, e}$ \\ aSchool of Basic Medical Sciences, Xinxiang Medical University, Xinxiang, 'bepartment of Pathology, \\ The First Affiliated Hospital of Xinxiang Medical University, Xinxiang, 'Department of Rheumatology, \\ First Hospital of Shanxi Medical University, Taiyuan, ${ }^{\mathrm{d} C}$ College of Pharmaceutical Sciences, Wenzhou \\ Medical University, Wenzhou, eInstitute of Precision Medicine, Xinxiang Medical University, Xinxiang, \\ China
}

\section{Key Words}

Fgf18 • Breast cancer $\cdot$ EMT $\cdot$ Akt/GSK3 $\beta / \beta$-catenin

\begin{abstract}
Background/Aims: Fibroblast growth factors (FGFs) and their high-affinity receptors contribute to autocrine and paracrine growth stimulation in several human malignant tumors, including breast cancer. However, the mechanisms underlying the carcinogenic actions of FGF18 remain unclear. Methods: The transcription level of FGF18 under the hypoxic condition was detected with quantitative PCR (qPCR). A wound-healing assay was performed to assess the role of FGF18 in cell migration. A clonogenicity assay was used to determine whether FGF18 silencing affected cell clonogenicity. Western blotting was performed to investigate Akt/GSK3 $\beta / \beta$-catenin pathway protein expression. Binding of $\beta$-catenin to the target gene promoter was determined by chromatin immunoprecipitation (ChIP) assays. Results: FGF18 promoted the epithelial-mesenchymal transition (EMT) and migration in breast cancer cells through activation of the Akt/GSK3 $\beta / \beta$-catenin pathway. FGF18 increased Akt-Ser473 and -Thr308 phosphorylation, as well as that of GSK3 $\beta$-Ser9. FGF18 also enhanced the transcription of proliferation-related genes (CDK2, CCND2, Ki67), metastasis-related genes (TGF- $\beta$, MMP- 2 , MMP-9), and EMT markers (Snail-1, Snail-2, N-cadherin, vimentin, TIMP1). $\beta$-catenin bound to the target gene promoter on the ChIP assay. Conclusion: FGF18 contributes to the migration and EMT of breast cancer cells following activation of the Akt/GSK3 $\beta / \beta$-catenin pathway. FGF18 expression may be a potential prognostic therapeutic marker for breast cancer.
\end{abstract}

N. Song, J. Zhong and Q. Hu contributed equally to this work.

(C) 2018 The Author(s)

Published by S. Karger AG, Basel

Haijun Wang

and Xianwei Wang
School of Basic Medical Sciences, Xinxiang Medical University

Jinsui Road 601, Xinxiang 453003, Henan (China)

Tel.+86-373-3029-123, E-Mail wnavy200299@163.com; wangxianwei1116@126.com 


\section{Cellular Physiology Cell Physiol Biochem 2018;49:1060-1073 \begin{tabular}{ll|l} 
and Biochemistry & Published online: 6 September, 2018 & (c) 2018 The Author(s). Published by S. Karger AG, Basel \\
wwrger.com/cpb
\end{tabular}

\section{Introduction}

Breast cancer, first recognized by the Egyptians more than 3500 years ago [1], is currently the most common form of cancer and the second leading cause of death from cancer among women. An estimated 1 to 1.3 million breast cancer cases are diagnosed annually worldwide. Breast cancers can be divided into molecular subtypes based on the expression of estrogen receptor (ER), progesterone receptor (PR), and human epidermal growth factor receptor 2 (HER2). Moreover, with the development of genetic diagnostic techniques such as cDNA microarrays, a novel classification system for breast cancer has been introduced, with the $\mathrm{ER}^{+}$group divided into at least three subgroups [2]. These cancers can be treated with hormone therapy as an effective and significantly less toxic alternative to chemotherapy. Among the subtypes, triple-negative (ER-, $\mathrm{PR}^{-}$, and HER2-) breast cancers have a particularly poor prognosis. In addition, the expression of proliferative markers such as Ki-67 is used for further prognostic distinction of molecular subtypes [3].

Over the past few decades, our understanding of breast cancer and its treatment has undergone a metamorphosis, shifting from generally indiscriminate to a more personalized approach based on gene expression analysis and the development of markers that can aid informed diagnostic and treatment decisions [2, 4-12]. Recently, a new panel of markers involving the relative expression of FGF18, BCL2, PRC1, MMP-9, and SERF1A was identified and validated for risk prediction in early breast cancer [8].

FGF18 is a $21.2 \mathrm{kDa}$ glycosylated secretory protein that is highly conserved among humans, mice, and rats. The structure of FGF18 is similar to that of FGF8 and FGF17, which together constitute the FGF8 subfamily [13]. As a mitogenic, chemotactic, and angiogenic factor, FGF18 is essential for the embryonic and postnatal development of multiple tissues, such as bone, cartilage, hair, and vasculature [13-16]. Overexpression of FGF18 has been frequently identified in synovial sarcoma, hepatocellular carcinoma, and colon and ovarian cancers [17-21]. FGF18 is also an informative prognostic and therapeutic biomarker for a subset of ovarian cancers [20,21].

Despite the apparent importance of FGF18 in the pathogenesis of ovarian and breast cancers, few studies have addressed the mechanistic aspects of FGF18 in tumorigenesis. The purpose of this study was to investigate the role of FGF18 in migration and the epithelialmesenchymal transition (EMT) and to determine why it preferentially reappears in hormonal cancers.

\section{Materials and Methods}

\section{Cell culture}

MCF-7, MDA-MB-453, SK-BR-3 and T47D breast cancer cell lines were obtained from the American Type Culture Collection (ATCC; Manassas, VA), and cultured in HyClone ${ }^{\mathrm{TM}}$ High-Glucose DMEM medium (Thermo, Cat. SH30243.01B) supplemented with 10\% fetal bovine serum (Gibco, Cat. 10099-133) and 1\% penicillin/streptomycin (Thermo, Cat. 15140122).

\section{TCGA and OncoLnc analyses}

The FGF18 mRNA expression and the FGF18 gene copy number of clinical breast cancer tissues were examined with Oncomine web (https://www.oncomine.org/resource/main.html), which the data based on The Cancer Genome Atlas (TCGA). In the Oncomine web, we set the filter as following: Gene: FGF18; Analysis type: Cancer vs. Normal Analysis; Cancer type: Breast cancer. The results were displayed as following: Group by: Cancer and normal type; Fingure type: Box-plot. The detail instructions for use, please refer to the Oncomine Support Community (https://support.oncomine.com/?authToken=1fc8a8a156c3ae215016c1ba 3d804575). The survival rates of the patients with FGF18 expression based on website of OncoLnc (http:// www.oncolnc.org/). In the OncoLnc web, we set the filter as following: Target gene: FGF18; Cancer type: Breast cancer. The detail instructions for use, please refer to the Guide to OncoLnc: A new TCGA data portal (https://www.Incrnablog.com/guide-to-using-oncolnc-a-new-tcga-data-portal/). 


\section{Cellular Physiology Cell Physiol Biochem 2018;49:1060-1073 \begin{tabular}{ll|l} 
and Biochemistry & Published online: 6 September, 2018 & (c) 2018 The Author(s). Published by S. Karger AG, Basel \\
wwrger.com/cpb
\end{tabular}}

\section{Wound-healing assays}

Wound healing assay was carried out to determine migration of breast cancer cells. In brief, MDAMB-453 and SK-BR-3 cells were grown to 80\% confluences in 6-wells plates. Wounds were created by scraping the cells with a sterile $200 \mu$ pipette tip, then cells were washed with warmed PBS and cultured in complete medium with the different concentration of recombinant FGF-18 (Thermo, Cat. PHG0234) at $37^{\circ} \mathrm{C}$. Images were taken at 48 and $96 \mathrm{~h}$ after scratching with an Eclipse TS100 microscope (Nikon).The migrating distance was quantified by determining the width between the edges of the injured monolayer of cells.

\section{Small interfering RNA (siRNA) assay}

siRNA targeting human FGF18 (NCBI Reference Sequence: NM_003862.2) and scrambled small interfering RNA (si-scrambled) were obtained from Sangon Biotech, Shanghai, China. A 19-nucleotide (nt), FGF18-specific, double-stranded siRNA (siFGF18) sequence: 5'- CCTGCACTTGCCTGTGTTT-3'; scramble siRNA (siSCR) as the control, 5'- CCTTCACGTGTCGTGCTTT-3'. siRNAs were transfected into MDA-MB453 cells at $30 \mathrm{nM}$ with the Lipofectamine RNAiMAX from Thermo Fisher Inc (Cat. 13778030) according to the manufacturer's instructions. The cells were incubated for at least $24 \mathrm{~h}$ before the analyses were carried out.

\section{Clonogenicity assay}

Forty-eight hours after transfection (described as siRNA), cells were plated at a low density in a DMEM medium containing $10 \%$ fetal bovine serum (FBS). After 10 days in culture, the cancer cells formed colonies, which were stained with methyl violet. Colony numbers were quantified by counting colonies that contained more than 25 cells observed under a light microscope. The numbers of clones were determined in at least three dishes per group. The statistical analyses for $\mathrm{p}$ values were obtained using SPSS18.0 software (SPSS, Inc., Chicago, IL, USA).

RNA isolation and quantitative reverse-transcriptase PCR ( $P$ PCR)

Total RNAs were isolated using the RNeasy Mini Kit (QIAGEN, Cat. 74104). $1 \mu \mathrm{g}$ total RNAs were reversely transcribed into cDNAs using a Super Script ${ }^{\circledR}$ First-Strand Synthesis System for RT-PCR Kit (Thermo, Cat. 11904018). qPCR was performed with SYBR ${ }^{\circledR}$ Select Master Mix (Thermo, Cat. 4472918) using StepOne Plus real-time PCR system (Applied Biosystems). Results were normalized to those obtained with $\beta$-Actin mRNA and presented as fold vs. control. Each experiment was performed in triplicate. Human Primers:

ß-Actin, F:5'-GCACAGAGCCTCGCCTT-3', R:5'-GTTGTCGACGACGAGCG-3';

FGF8, F:5'-ATCGTGGAGACGGACACCTT-3', R:5'-GCGATCAGCTTCCCCTTCTT-3';

FGF17, F:5' -GCTGCTGATTCTCTGCTGTCAA-3', R:5'-GCTCAGCTGGTCGGTCATG-3';

FGF18, F:5'-TGCTTCCAGGTACAGGTGCT-3', R:5'-GCTGCTTACGGCTCACATCG-3';

CDK2, F:5'-ACACGCTGCTGGATGTCATTC-3', R:5'-CCTGGAGCAGCTGGAACAG-3';

CCND2, F:5'-TGGGGAAGTTGAAGTGGAAC-3', R:5'-ATCATCGACGGTGGGTACAT-3';

Ki67, F:5'-TTCGCAAGCGCATAACCCA-3', R:5'-AACCGTGTCACAGTGCCAAA-3';

TGF- $\beta$, F:5'-GTACCTGAACCCGTGTTGCT-3', R:5'-CAACTCCGGTGACATCAAAA-3';

MMP-2, F:5'-TGACTTTCTTGGATCGGGTCG-3', R:5'-AAGCACCACATCAGATGACTG-3';

MMP-9, F:5'-CCCGGACCAAGGATACAGTTT-3', R:5'-GTGCCGGATGCCATTCAC-3';

Snail-1, F:5'-CCCAATCGGAAGCCTAACTA-3', R:5'- GGACAGAGTCCCAGATGAGC-3';

Snail-2, F:5'-CCTTCCTGGTCAAGAAGCAT-3', R:5' - CACAGTGATGGGGCTGTATG-3';

E-Cadherin, F:5'-TCATGAGTGTCCCCCGGTAT-3', R:5'- CGGAACCGCTTCCTTCATAG-3';

N-Cadherin, F:5'-CTGGATCGCGAGCAGATAGC-3', R:5' - CCCATTCCAAACCTGGTGTAA-3';

Vimentin, F:5'-GGCTCAGATTCAGGAACAGC-3', R:5'- AGCCTCAGAGAGGTCAGCAA-3';

TIMP-1, F:5'-GGGACACCAGAAGTCAACCA-3', R:5'-GTTGTGGGACCTGTGGAAGT-3'.

\section{Western blotting assay}

2-5 $\times 10^{6}$ cells were lysed with $1 \mathrm{ml}$ of lysis buffer (50 mM Tris-HCl, pH7.2, 1\% NP-40, $150 \mathrm{mM} \mathrm{NaCl}$, $50 \mathrm{mM} \beta$-Glycerophosphate disodium salt hydrate, $5 \mathrm{mM}$ DL-Dithiothreitol, $0.1 \mathrm{mM}$ PMSF) plus protease inhibitors (Sigma-Aldrich) for $30 \mathrm{~min}$ on ice. After centrifugation at $10000 \mathrm{rpm}$ for $15 \mathrm{~min}$ at $4^{\circ} \mathrm{C}$, the lysates were boiled with $5 \times$ sample buffer, then separated by SDS-PAGE and transferred to PVDF membrane. 


\section{Cellular Physiology Cell Physiol Biochem 2018;49:1060-1073 \begin{tabular}{ll|l} 
and Biochemistry & Published online: 6 September, 2018 & (c) 2018 The Author(s). Published by S. Karger AG, Basel \\
wwrger.com/cpb
\end{tabular}}

Immunoblotting was performed as described [22] and visualized by chemiluminescence (Bio-Rad, Series No. ChemiDoc XRS+). Antibodies used for immunoblotting were as follows: FGF18 (Abcam, Cat. Ab86571), Akt (Santa Cruz, Cat. sc-8312), p-Akt Ser473 (Santa Cruz, Cat. sc-7985-R), p-Akt Thr308 (Santa Cruz, Cat. sc16646-R), p-GSK3 $\beta$ Ser9 (Cell Signaling, Cat. \#9323), p-GSK3 $\beta$ Tyr216 (Santa Cruz, Cat. sc-135653), GSK3 $\beta$ (Santa Cruz, Cat. sc-9166), $\beta$-catenin (Cell Signaling, Cat. \#8480), Actin (Santa Cruz, Cat. sc-1616-R) and anti-rabbit IgG antibodies conjugated to horseradish peroxidase (Abcam, Cat. ab6721).

\section{Chromatin immunoprecipitation(ChIP) and quantitative ChIP (qChIP)}

qChIP assay was performed as reported previously [22, 23]. Briefly, $2 \times 10^{7}$ MDA-MB-453 cells were collected by centrifugation at $2000 \mathrm{~g}$ for $5 \mathrm{~min}$ at room temperature and cross-linked in PBS containing $1 \%$ formaldehyde for $10 \mathrm{~min}$ on ice. The reaction was stopped by adding glycine to a final concentration of 0.125 M. ChIP assay was performed by incubation of the chromatin with $20 \mu \mathrm{L}$ rabbit mAb $\beta$-catenin antibody (Cell Signaling, Cat. \#8480) or normal rabbit IgG (Cell Signaling, Cat. \#2729). Enrichment of the ChIP sample over input was evaluated by qPCR with specific primers in the promoter region of target genes. Three technical replicates were performed. Fold enrichment was calculated by the formula: $2^{\text {-cTsample/2-ctinput }}$ qChIP primers for target gene promoter and location relative to TSS (Transcript Start Site, TSS):

CDK2 (-541 to -463bp), F: 5'-GGTCACTCTCATCTTGAT-3', R: 5'-AACTGTTGTGTCTGGTAT-3'. CCND2 (-396 to -518bp), F: 5'- GTATGCGAGGTTGCTATT, R:5'-TTAAGATCCAGGAATGTAGG-3'. Ki67 (-306 to -381bp), F: 5'-AATCTTCTGGCAATGAGTAATGT-3', R: 5'-ATAACCCGTCCTGCTATCC-3'. TGF- $\beta$ (-508 to -618bp), F: 5'-TTCCCTATCTGTAAATTGG-3', R: 5'-GTAAGAATTGCTCTCCTT-3'. MMP-2 (-254 to -356bp), F: 5'-CAAGTTAAGGCTTACACATT-3', R: 5'-GGATGAACAGAGATGGAA-3'. MMP-9 (-931 to -1006bp), F: 5'-TGTATCCTTGACCTTCTT-3', R: 5'-CATTCCTGTAATCTTAGCA-3'. N-Cadherin (-793 to -872bp), F: 5'-CACCATTCTTCATCTCCATTAG-3', R: 5'-ATAACTTGGGCAGGAACTT-3'. Snail-1 (-753 to -891bp), F: 5'-CCTTGATAATTCTTCACT-3', R: 5'-GACGAAGTAAACAGATAA-3'. Snail-2 (-332 to -421bp), F: 5'-GCAATCTTCCAGTTCTTCC-3', R: 5'-TACTCATGTCACCGTGTTAG-3'. Vimentin (-861 to -966bp), F: 5'-GTCCTGTAATTCCACCTT-3', R: 5'-GAGCGTATTCTGACTTCT-3'. TIMP1 (-140 to -277bp), F: 5'- ATAGCAATTAGGAATCAGTATAG-3', R: 5' - TTCTCAACATTGGCATTAG-3'.

\section{Statistical Analysis}

All data are expressed as mean \pm standard deviation at least three independent experiments. Twotailed $p$-value less than 0.05 was viewed as statistically significant (displayed as ${ }^{*} p<0.05,{ }^{* *} p<0.01,{ }^{* * *} p$ $<0.001$ ). All analyses were performed using SPSS 19.0 software (Statistical Package for Social Studies, Chicago, IL, USA).

\section{Results}

\section{FGF18 expression and its relationship with breast cancer patient survival}

To clarify the relationship between FGF18 expression and breast cancer incidence, we examined FGF18 expression and gene copy number via the Oncomine website (https:// www.oncomine.org/resource/main.html) [24], which is based on The Cancer Genome Atlas database (https://cancergenome.nih.gov/). FGF18 mRNA levels $(n=582)$ and gene copy number $(n=229)$ were significantly increased in breast cancer samples compared with normal breast tissues (Fig. 1A-B). Furthermore, analysis of FGF18 protein content using the Human Protein Atlas database (http://www.proteinatlas.org/) revealed that FGF18 tended to be highly expressed in breast cancer samples compared with normal tissue (Fig. 1C).

Next, we analyzed the survival rates of patients with high $(n=150)$ and low $(n=150)$ levels of FGF18 expression based on the OncoLnc website (http://www.oncolnc.org/) [25]. As shown in Fig. 1D, a higher expression of FGF18 was associated with worse breast cancer patient survival. Altogether, the high expression of FGF18 appears to be a biomarker of poor prognosis, which indicates that FGF18 may play a significant role in the development of breast cancer. 


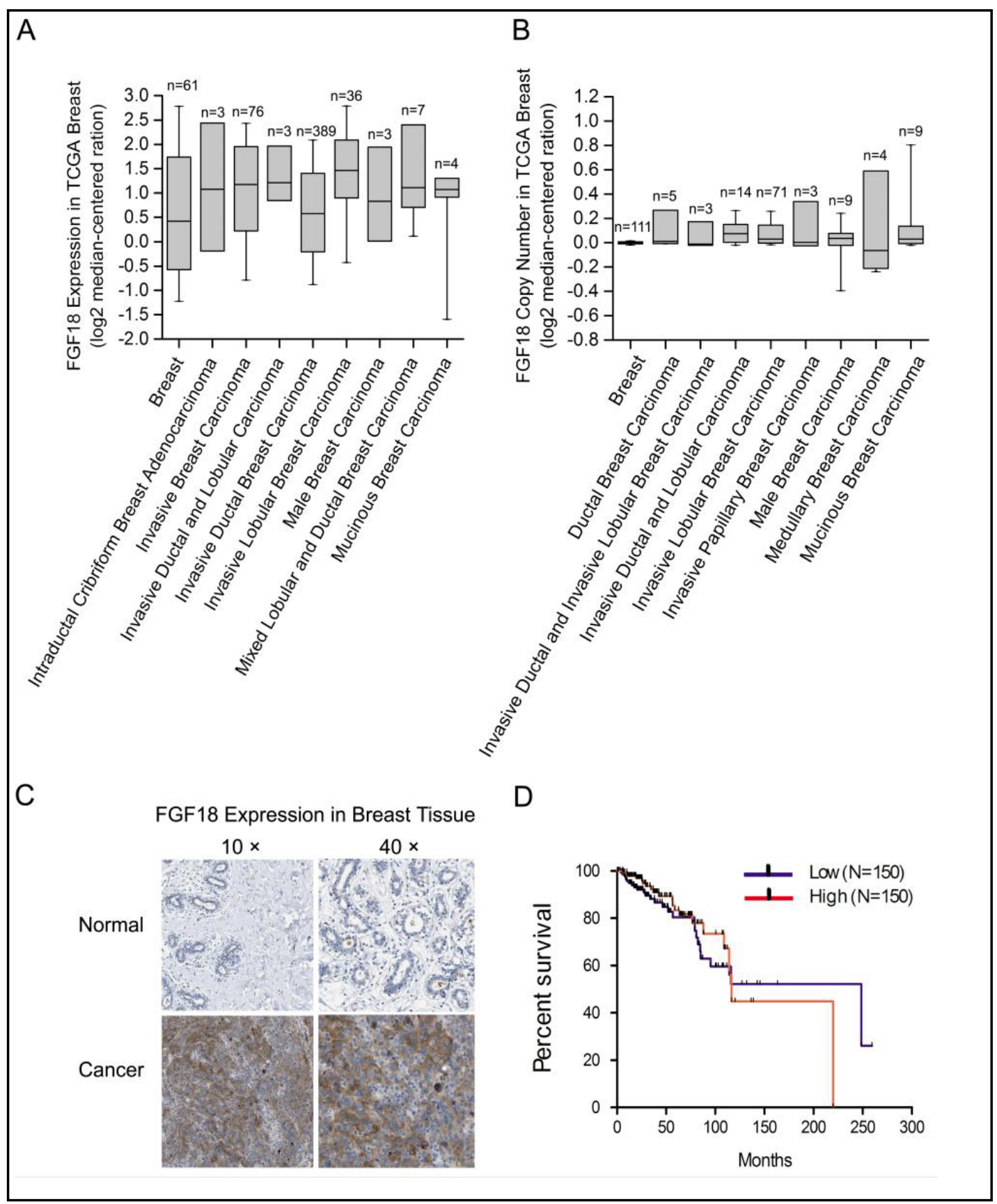

Fig. 1. FGF18 expression in breast cancer tissues and its relationship with the survival of patients with breast cancer. (A) FGF18 expression in different breast cancers $(n=582)$ based on TCGA breast cancer database. Normal breast tissues $(n=61)$, intraductal cribriform breast adenocarcinoma $(n=3)$, invasive breast carcinoma $(n=76)$, invasive ductal and lobular carcinoma $(n=3)$, invasive ductal breast carcinoma $(n=389)$, invasive lobular breast carcinoma $(n=36)$, male breast carcinoma $(n=3)$, mixed lobular and ductal breast carcinoma ( $n=7)$, mucinous breast carcinoma $(n=4)$. (B) FGF18 gene copy number in different breast cancers $(n=229)$ based on TCGA breast cancer database. Normal breast tissues $(n=111)$, ductal breast carcinoma $(n=5)$, invasive ductal and invasive lobular breast carcinoma $(n=3)$, invasive ductal and lobular carcinoma $(n=14)$, invasive lobular breast carcinoma $(n=71)$, invasive papillary breast carcinoma $(n=3)$, male breast carcinoma $(n=9)$, medullary breast carcinoma $(n=4)$, mucinous breast carcinoma $(n=9)$. (C) FGF18 expression in breast cancer by immunohistochemistry (IHC) staining. (D) The overall survival rates of breast cancer patients with high $(n=150)$ and low level $(n=150)$ of FGF18.

\section{KARGER}


Upregulation of FGF8 family genes in breast cancer cell lines under hypoxic conditions

Rapidly growing tumors such as breast cancer often suffer from an inadequate blood supply. Hypoxia is one of the inducers of breast cancer development that causes breast cell damage via increased reactive oxygen species (ROS) production [26]. Therefore, we wondered whether a lack of oxygen leads to the upregulation of the FGF8 subfamily in breast carcinoma. When the breast cancer cell lines MCF-7, MDA-MB-453, SK-BR-3, and T47D were cultured with the hypoxia-mimetic drug deferoxamine mesylate for $48 \mathrm{~h}$, the transcript levels of FGF8, FGF17, and FGF18 were increased up to 20 -fold within $48 \mathrm{~h}$ above the already considerable expression levels in control cultures (Fig. 2). These results demonstrated that hypoxia could induce the expression of the FGF8 subfamily.

\section{Effects of FGF18 on cell migration in MDA-MB-453 and SK-BR-3 cells}

To investigate whether FGF18 expression increases cancer cell motility, a wound-healing assay was performed in MDA-MB-453 and SK-BR-3 cells treated with $10 \mathrm{ng} / \mathrm{ml}$ and $20 \mathrm{ng} / \mathrm{ml}$ FGF18. FGF18-treated cells were able to migrate more rapidly, with the migration distance dependent on the FGF18 concentration (Fig. 3A-D). We also observed that MDA-MB-453 cells were more sensitive to FGF18 stimulation than SK-BR-3 cells, and therefore chose the MDA-MB-453 cell line for further analyses.

\section{FGF18 silencing reduces clone formation in MDA-MB-453 cells}

To assess the role of FGF18 in the malignant behavior of MDA-MB-453 cells, the expression of FGF18 was knocked down by small interfering RNA (siRNA). As shown in Fig. 3E, FGF18 siRNA significantly decreased both the protein and mRNA expression levels of FGF18 compared with scrambled siRNA. More importantly, knockdown of FGF18 also markedly decreased the clonal formation ability of MDA-MB-453 cells (Fig. 3F).

Fig. 2. The expression profile of fibroblast growth factor 8 subfamily (FGF8, FGF17, FGF18) under the induced hypoxic condition. Breast cancer cells were treated with $100 \mu \mathrm{M}$ deferoxamine mesylate for $48 \mathrm{~h}$. Cells were harvested for total RNA extraction. Expressions of FGF8, FGF17, and FGF18 mRNA were determined by qPCR. (A) MCF-7 cells. (B) MDAMB-453 cells. (C) SK-BR-3 cells. (D) T47D cells. DM: deferoxamine mesylate. The $\beta$-Actin RNA was used as an internal control for all qPCR analysis. The quantified data from three independent experiments are shown as means and standard errors. ${ }^{*} \mathrm{p}<0.05$, ${ }^{* *} \mathrm{p}<0.01,{ }^{* * *} \mathrm{p}<0.001$.
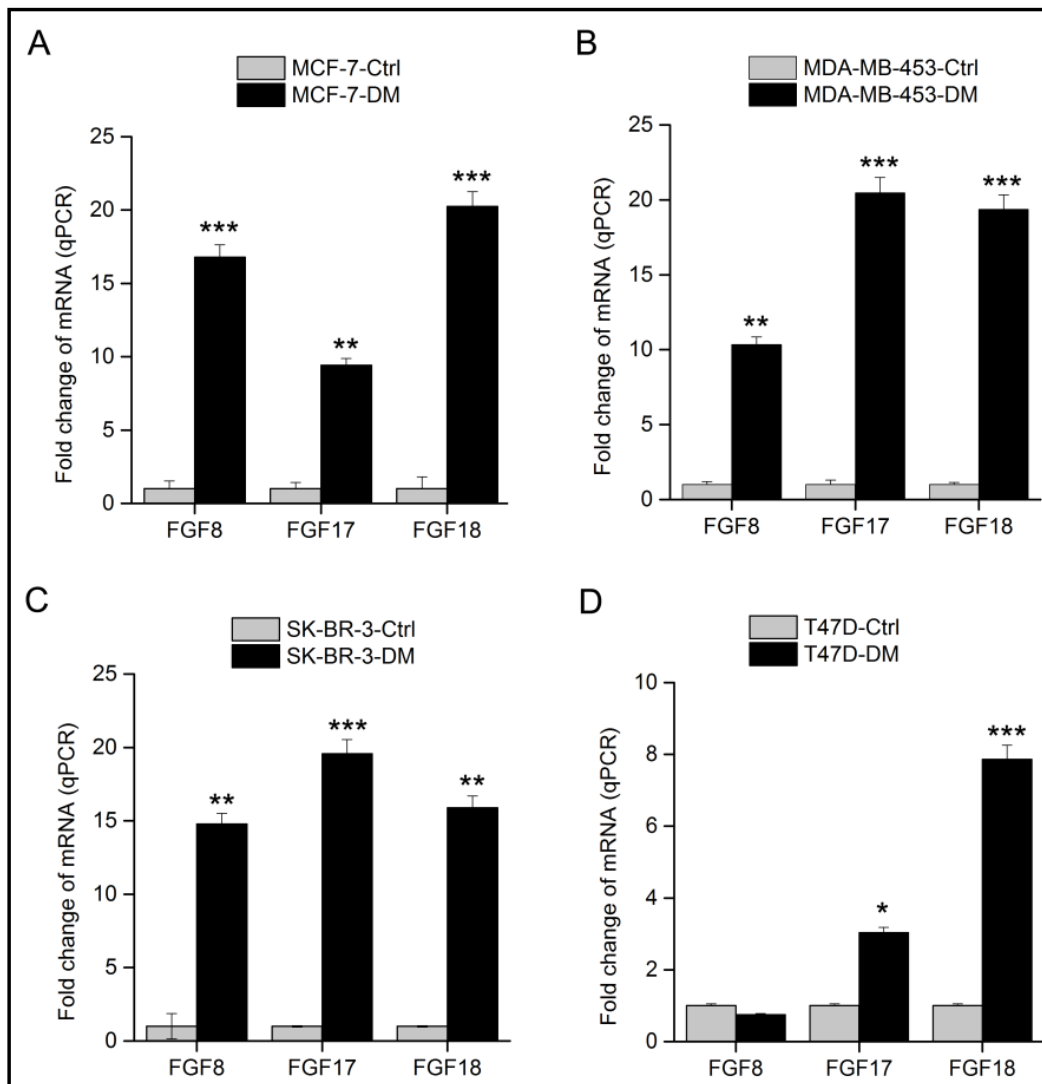

D

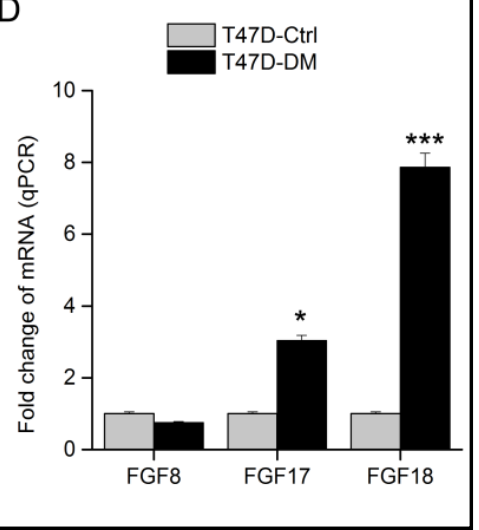




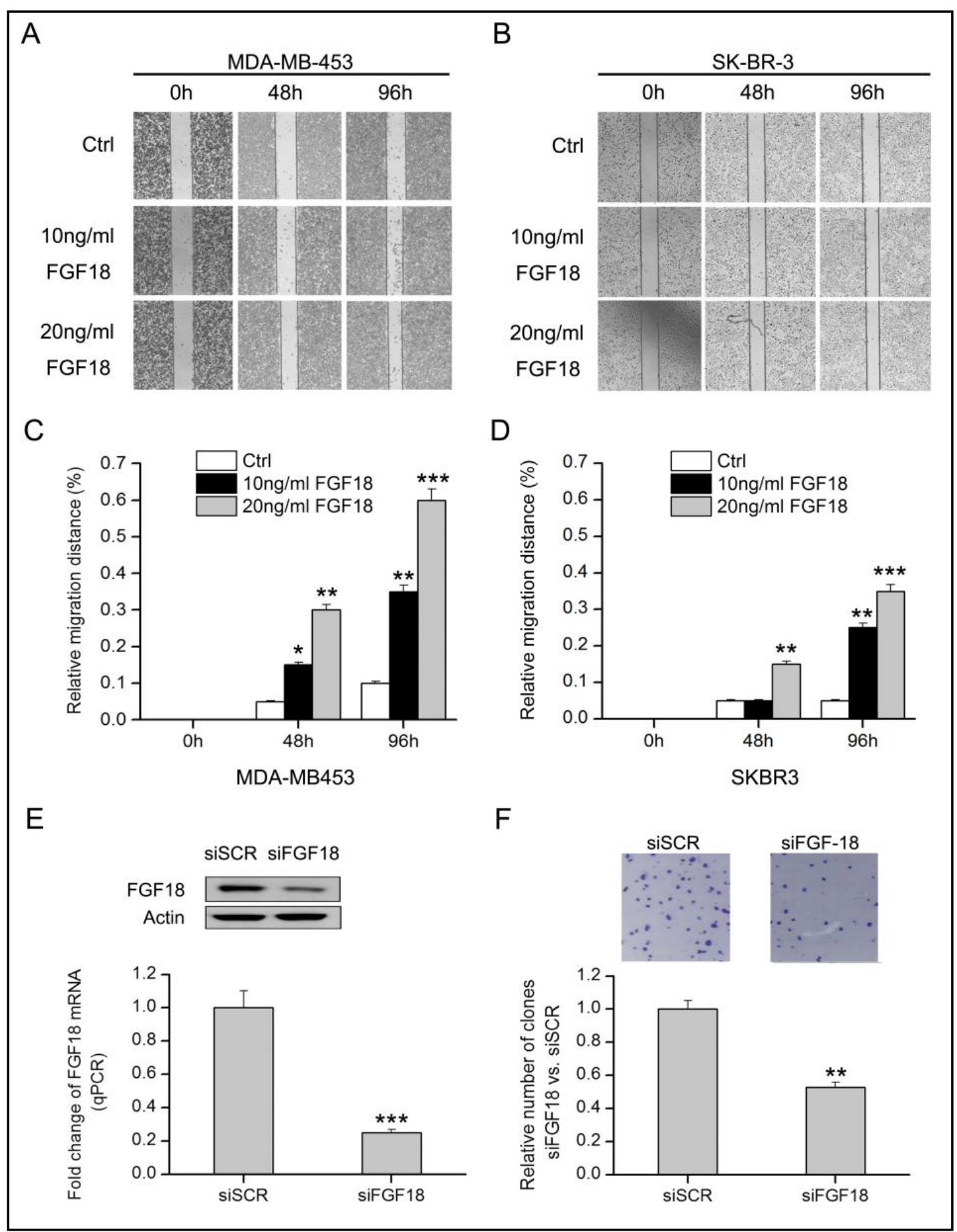

Fig. 3. Effect of FGF18 on migration of MDA-MB-453 and SK-BR-3 cells. Breast cancer cells were treated with $10 \mathrm{ng} / \mathrm{ml}$ or $20 \mathrm{ng} / \mathrm{ml} \mathrm{FGF18} \mathrm{for} \mathrm{0,} 48$ and $96 \mathrm{~h}$. (A) MDA-MB-453 cells; (B) SK-BR-3 cells, magnifcation, 40x. (C-D) The relative distance plot according to the data from A and B. (E) The impact of FGF18-siRNA on the expression level of the gene was determined by Western blotting and qRT-PCR. (F) Representative clones of MDA-MB-453 cells formed after the treatment with siSCR or siFGF18. Results are shown as means \pm SD from three experiments in triplicates. ${ }^{*} \mathrm{p}<0.05,{ }^{* *} \mathrm{p}<0.01,{ }^{* * *} \mathrm{p}<0.001$. 
Effects of FGF18 on the expression of proliferation-, migration-, and EMT-related genes in MDAMB-453 cells

To explore FGF18-mediated downstream events, we isolated total RNA from MDA-MB-453 cells treated with $10 \mathrm{ng} / \mathrm{ml}$ FGF18 and performed qRTPCR to assess the expression levels of target genes related to proliferation, migration, and the EMT. Proliferation-related genes, including CDK2, CCND2, and Ki67, were significantly upregulated in MDAMB-453 cells exposed to $10 \mathrm{ng} / \mathrm{ml}$ FGF18 (Fig. 4A). The expression levels of TGF- $\beta$, MMP-2, and MMP9 , which are involved in tumor migration activities, were notably increased after FGF18 treatment (Fig. 4B). The EMT markers, including Snail-1, Snail-2, N-cadherin, vimentin, and TIMP-1, were also significantly upregulated in response to FGF18 stimulation. In contrast, the expression of E-cadherin was significantly decreased in MDA-MB-453 cells after treatment with FGF18 (Fig. 4C). E-cadherin is one of the epithelial molecular markers that is always downregulated during EMT progression [27, 28].

Effects of FGF18 on Akt/GSK3 $/ \beta$-catenin signaling in $M D A-M B-453$ cells

To further explore whether FGF18 promotes carcinogenesis in breast cancer by activating the Akt pathway, we performed western blotting. As shown in Fig. 5, the expression levels of phospho-Akt-Ser473 (p-Akt-Ser473) and phospho-Akt Thr308 (p-AktThr308) were increased after FGF18 treatment in a dose-dependent manner. Both phosphorylation sites are indicative of Akt activation. We next tested GSK3 $\beta$ expression, which is a main downstream target of Akt activation. FGF18 treatment was followed by phosphorylation of Ser9 (p-GSK3 $\beta$-Ser9), but not Tyr216 (p-GSK3 $\beta$-Tyr216). The total $\beta$-catenin level was also found to be upregulated in the FGF18treated cells, suggesting a downstream link to the changes in EMT-related gene expression. Overall, our findings indicate that FGF18 regulates the genes related to breast carcinogenesis via Akt/GSK3 $\beta$ mediated $\beta$-catenin signaling (Fig. 5).

To further ascertain how $\beta$-catenin regulates proliferation-, migration-, and EMT-related genes, we performed a chromatin immunoprecipitation assay (ChIP) and quantitative ChIP with $\beta$-catenin antibody in MDA-MB-453 cells. As shown in Fig. 6, ChIP analysis revealed that $\beta$-catenin bound to the promoters of CDK2, CCND2, and Ki67, as well as several migration (TGF- $\beta$, MMP-2, MMP-9)- and EMT (Snail-1, Snail-2, $\mathrm{N}$-cadherin, vimentin, and TIMP1)-related genes.

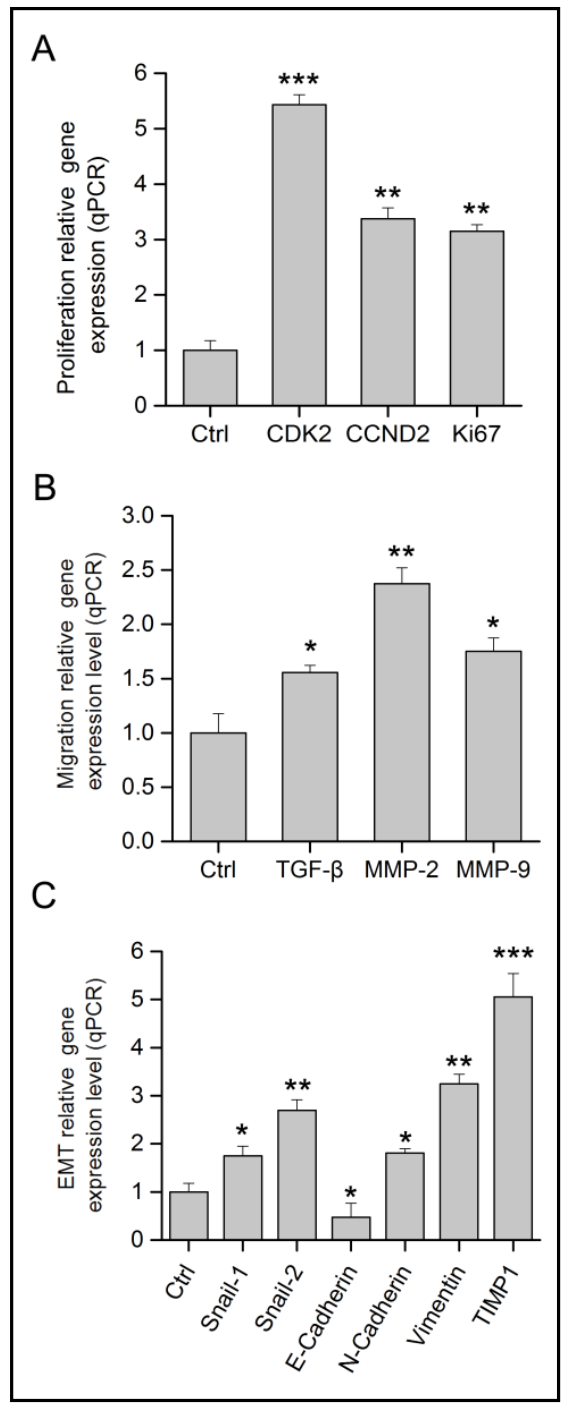

Fig. 4. Gene expression profile following FGF18 treatment. MDA-MB-453 cells were treated with $10 \mathrm{ng} / \mathrm{ml}$ FGF18 for 48h, and then CDK2, CCND2, Ki67, TGF- $\beta$, MMP-2, MMP-9, Snail-1, Snail-2, N-Cadherin, Vimentin, TIMP1 mRNA expressions were measured by qPCR. (A) Proliferation related gene expression: CDK2, CCND2, Ki67. (B) Migration related gene expression: TGF- $\beta$, MMP-2, MMP-9. (C) EMT related gene expression: Snail1,Snail-2, N-Cadherin, Vimentin, TIMP1. Results are shown as means \pm SD from three experiments in triplicates. ${ }^{*} \mathrm{p}<0.05$, ${ }^{* *} \mathrm{p}<0.01,{ }^{* * *} \mathrm{p}<0.001$. 


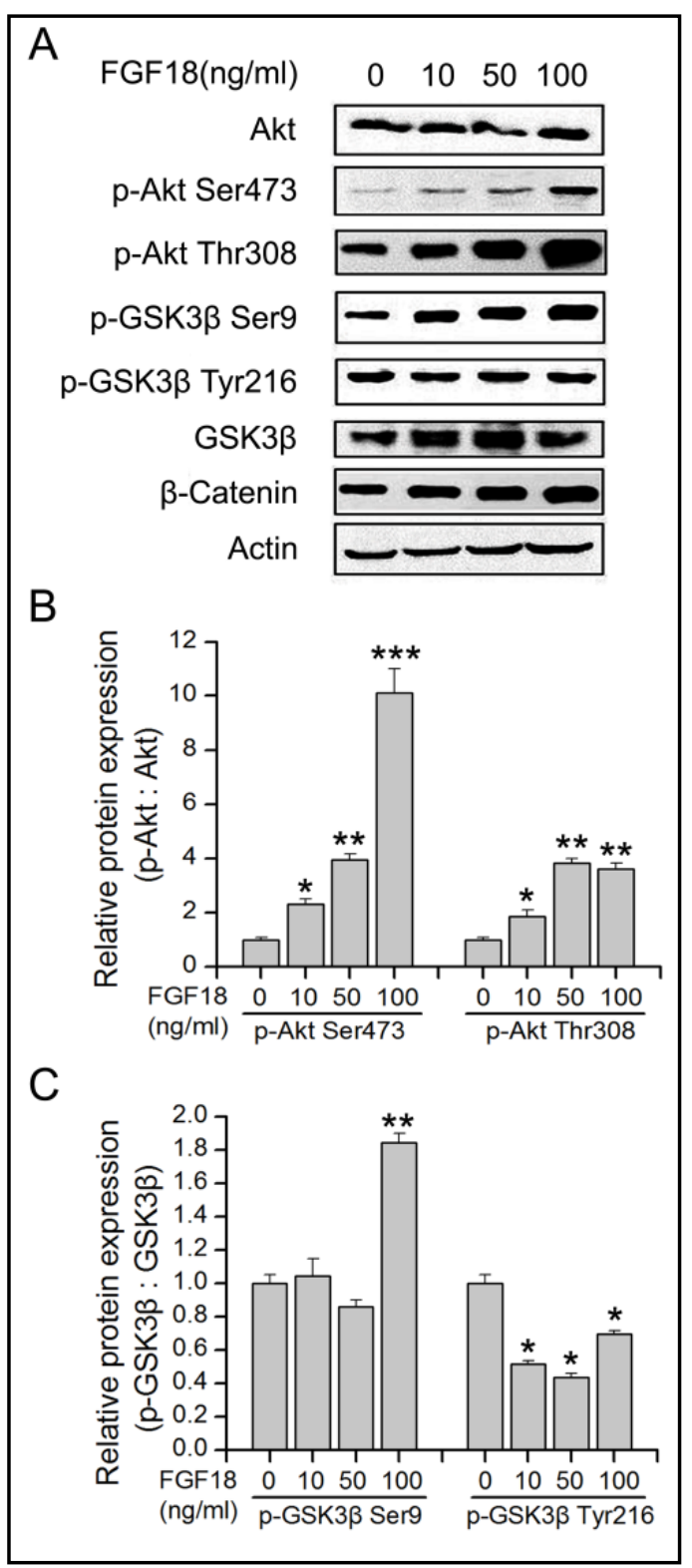

Fig. 5. The effect of FGF18 on Akt/GSK3 $\beta / \beta$ Catenin signaling pathway. (A) MDA-MB-453 cells were incubated with $10,50,100 \mathrm{ng} / \mathrm{ml} \mathrm{FGF18} \mathrm{for}$ $48 \mathrm{~h}$, and then harvested for total protein extraction. Protein samples were separated on $12.5 \%$ sodium dodecyl sulfate gels for immunoblotting. The blots shown in the figure represent averages of three independent experiments (mean \pm SD). Image J software (version 1.48, NIH, USA) was used to make the quantitative analysis of phosphorylation of Akt-Ser473 and -Thr308 (B), GSK3 $\beta$-Ser9 and GSK3 $\beta$-Tyr216 (C).

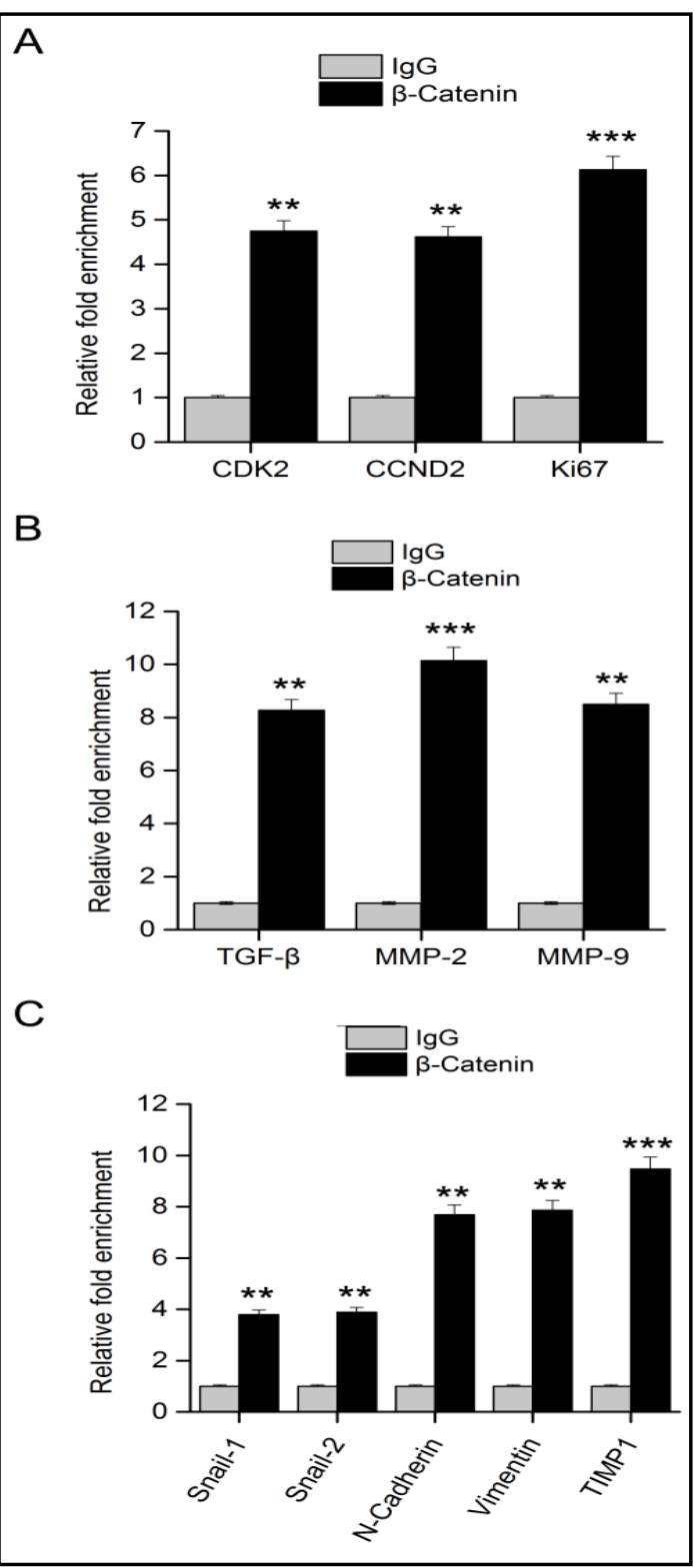

Fig. 6. FGF18 upregulated target genes expression via Akt/GSK3 $\beta / \beta$-Catenin signaling pathway. Chromatin immunoprecipitation (ChIP) was performed with $\beta$-Catenin antibody in MDA-MB-453 cells. qChIP assay was used to detect the $\beta$-Catenin binding to the upstream/promoter regions of target genes. (A) Proliferation related gene promoters: CDK2, CCND2, Ki67. (B) Migration related gene promoters: TGF- $\beta$, MMP-2, MMP-9. (C) EMT related gene promoters: Snail-1, Snail-2, N-Cadherin, Vimentin, TIMP1. Results are shown as means \pm SD of three experiments in triplicates. 


\section{Cellular Physiology Cell Physiol Biochem 2018;49:1060-1073

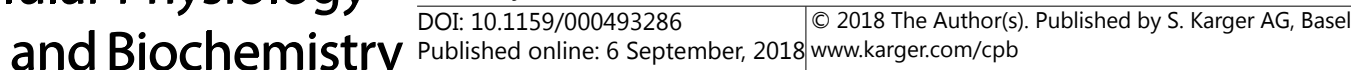 \\ Song et al.: FGF18 Promotes Migration and EMT in Breast Cancer}

\section{Discussion}

FGF18 is overexpressed in several types of tumors and has also been considered a potential prognostic and therapeutic biomarker [17-21]. FGF18 promotes the development and progression of hepatocellular malignancies, colorectal cancers, and synovial sarcomas by stimulating tumor cell growth or survival [17-19]. As a secreted protein, FGF18 controls migration, invasion, and tumorigenicity in ovarian cancer cells and, by increasing the production of oncogenic cytokines and chemokines, affecting the tumor microenvironment $[20,21]$. Because ovarian cancer is strongly associated with the basal-like subtype, a subtype regrouping of triple-negative breast cancer, we believe that FGF18 may also promote breast carcinogenesis $[2,29]$.

All mammalian FGF ligands activate one or more of four distinct cell-surface receptor tyrosine kinases (FGFR1-FGFR4). FGFR4, also called FGFR3c, is one of the receptors for FGF18 [21] and is implicated in the function of FGF18 as a mesenchymal growth factor $[30,31]$. In colorectal cancer, FGFR4 acts as an oncogene and FGF18 is upregulated as a $\beta$-catenin target gene $[18,32]$. The therapeutic potential of FGFR inhibitors is presently under investigation in clinical trials in breast cancer patients [33].

$\beta$-catenin is capable of enhancing FGF18 transcription because the promoter of human FGF18 harbors T cell factor/lymphoid enhancer-binding factor binding sites [34]. In our ChIP studies, we also found that $\beta$-catenin binds to the promoters of the proliferation, migration, and EMT genes being studied. The expression of FGF18, in combination with other markers, also predicts the risk of breast cancer [35]. However, although the importance of FGF18 is well established, the mechanisms underlying the involvement of FGF18 in breast cancer development and progression remain largely elusive. Here, we addressed this question using breast cancer cell lines in vitro.

In this study, we found pronounced overexpression of the FGF8 subfamily in human breast cancer cell lines under hypoxic conditions. We further found that FGF18 could increase the motility of cells in a time- and dose-dependent manner, as determined by tracking the distance traveled in a wound-healing assay. In agreement with the wound-healing results, genes involved in migration, including TGF- $\beta$, MMP-2, and MMP-9, were overexpressed in MDA-MB-453 cells after FGF18 treatment.

The EMT is a process that involves transition to the mesenchymal state and causes cells to gain migratory and invasive properties, key events in cancer metastasis [36-39]. Our results showed that the expression levels of cancer metastasis-related genes, such as Snail-1, Snail-2, N-cadherin, vimentin, and TIMP-1, were markedly increased after FGF18 treatment. In contrast, E-cadherin, an epithelial marker, was downregulated. These results suggest that FGF18 may induce the EMT and contribute to malignization through inhibition of E-cadherin expression and stimulation of EMT-related genes. In addition, we also concluded that the application of exogenous FGF18 could increase the expression of proliferation-related genes, such as CDK2, CCND2, and Ki67.

Akt/GSK3 $\beta$ signal pathway plays an important role in the development of tumors [40]. Our data indicate that FGF18 may promote breast carcinogenesis through the Akt/GSK3 $\beta / \beta$ catenin pathway. FGF18 induced the phosphorylation of Akt at Ser473 and Thr308 sites and inactivated GSK3 $\beta$ by elevating Ser9 modification, but not Tyr216. Based on the present data and the evidence available in the literature, we have outlined a hypothetical model to explain our findings (Fig. 7). In this model, FGF18 upregulates Akt phosphorylation at Ser473 and Thr308 sites and then triggers GSK3 $\beta$ phosphorylation at Ser9 (p-GSK3 $\beta$-Ser9, an inactive form of GSK3 $\beta$ ), but not Tyr216 (p-GSK3 $\beta$-Tyr216, an active form of GSK3 $\beta$ that mainly mediates the degradation of GSK3 $\beta$ ). As a result, the inactive GSK3 $\beta$ leads to $\beta$-catenin accumulation in the cytoplasm and its translocation to the nucleus, where $\beta$-catenin triggers the expression of multiple genes, such as CDK2, CCND2, Ki67, TGF- $\beta$, MMP-2, MMP-9, Snail-1, Snail-2, and N-cadherin, responsible for cell survival, migration, and the EMT [41].

The FGF18-mediated signaling in the breast cancer cell lines used in our study further confirms the utility of FGF18 as a reliable biomarker for cancer, as previously reported in 
Fig. 7. Schematic representation of FGF18mediated Akt/GSK3 $\beta / \beta$ Catenin signaling in breast cancer cells. FGF18 could promote carcinogenesis of breast cancer via the Akt/ GSK3 $\beta / \beta$-Catenin signaling pathway. The inactive $\beta$-Catenin modulates target gene expression through relocating into the nucleus and binding to the promoters of proliferation-, migration- and EMT-related genes.

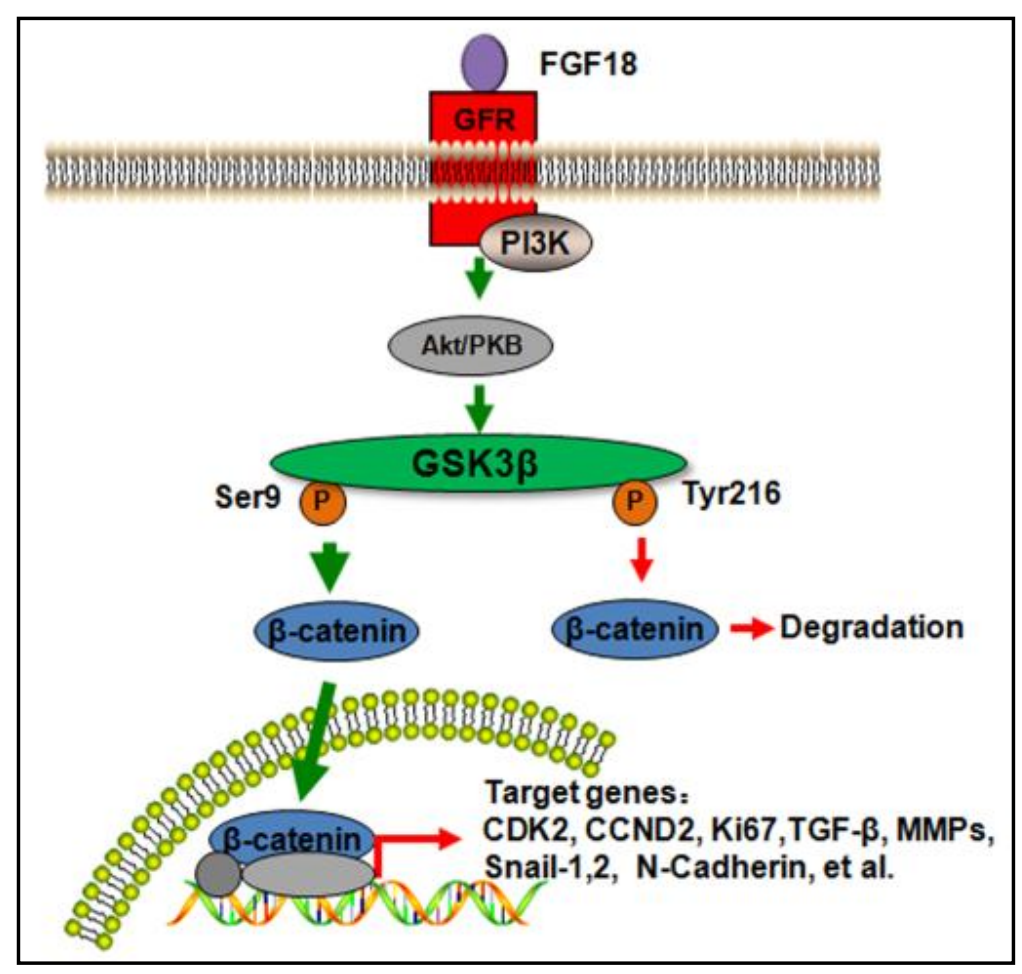

other systems [42-44]. However, the present study was limited to HER ${ }^{+}$breast cancer cell lines (MDA-MB-453, SKBR3) and not triple-negative breast cancercell lines. Thus, our results have to be confirmed in triple-negative breast cancer cells and in vivo.

\section{Conclusion}

In summary, our data demonstrate that FGF18 exerts oncogenic effects in $\mathrm{HER}^{+}$breast cancer cells by promoting cell proliferation and migration in vitro. This makes FGF18 a promising candidate target for basic study or clinical research in non-triple-negative breast cancers.

\section{Disclosure Statement}

The authors declare that no conflict of interest exist..

\section{Acknowledgements}

This work was supported by National Natural Science Foundation of China (Grant No. 81602132, 81702891), and grants from the Department of Science and Technology of Henan Province (Grant No. 182102310242, 172102310584, 172102310651), the Education Department of Henan Province (Grant No. 201610472017, 201610472040), Doctoral Scientific Research Foundation of Xinxiang Medical University (XYBSKYZZ201512\&201513), Zhejiang Provincial Natural Science Foundation (LQ13H280002). 


\section{Cellular Physiology Cell Physiol Biochem 2018;49:1060-1073 \begin{tabular}{l|l|l} 
and Biochemistry 2018 The Author(s). Published by S. Karger AG, Basel & (0).1159/000493286
\end{tabular}

\section{References}

1 Hellman S: Dogma and inquisition in medicine. Breast cancer as a case study. Cancer 1993; 71:2430-2433.

-2 Sørlie T, Perou CM, Tibshirani R, Aas T, Geisler S, Johnsen H, Hastie T, Eisen MB, van de Rijn M, Jeffrey SS, Thorsen T, Quist H, Matese JC, Brown PO, Botstein D, Lønning PE, Børresen-Dale AL: Gene expression patterns of breast carcinomas distinguish tumor subclasses with clinical implications. Proc Natl Acad Sci U S A 2001;98:10869-10874.

3 Lim B, Hortobagyi GN: Current challenges of metastatic breast cancer. Cancer Metastasis Rev 2016; 35:495514.

-4 Perou CM, Sørlie T, Eisen MB, van de Rijn M, Jeffrey SS, Rees CA, Pollack JR, Ross DT, Johnsen H, Akslen LA: Molecular portraits of human breast tumours. Nature 2000;406:747-752.

5 Albain KS, Paik S, van't Veer L: Prediction of adjuvant chemotherapy benefit in endocrine responsive, early breast cancer using multigene assays. Breast 2009;18:141-145.

-6 Peterse HL, van der Kooy K, Marton MJ, Witteveen AT, Schreiber GJ, Kerkhoven RM, Roberts C, Linsley PS, Bernards R, Friend SH: Gene expression profiling predicts clinical outcome of breast cancer. Nature 2002;415:530-536.

7 Mook S, Schmidt MK, Weigelt B, Kreike B, Eekhout I, van de Vijver MJ, Glas AM, Floore A, Rutgers EJ, van 't Veer LJ: The 70-gene prognosis signature predicts early metastasis in breast cancer patients between 55 and 70 years of age. Ann Oncol 2010;21:717-722.

-8 Mustacchi G, Sormani MP, Bruzzi P, Gennari A, Zanconati F, Bonifacio D, Monzoni A, Morandi L: Identification and Validation of a New Set of Five Genes for Prediction of Risk in Early Breast Cancer. Int J Mol Sci 2013;14:9686-9702.

9 Pongor L, Kormos M, Hatzis C, Pusztai L, Szabó A, Győrffy B: A genome-wide approach to link genotype to clinical outcome by utilizing next generation sequencing and gene chip data of 6697 breast cancer patients. Genome Med 2015;7:104.

$>10$ Cardoso F, van't Veer LJ, Bogaerts J, Slaets L, Viale G, Delaloge S, Pierga JY, Brain E, Causeret S, DeLorenzi M: 70-Gene Signature as an Aid to Treatment Decisions in Early-Stage Breast Cancer. N Engl J Med 2016;375:717-729.

11 Naoi Y, Noguchi S: Multi-gene classifiers for prediction of recurrence in breast cancer patients. Breast Cancer 2016;23:12-18.

12 Xiao M, Yang S, Meng F, Qin Y, Yang Y, Jia S, Cai X, Li C, Huang Y, Ning X: LAPTM4B Predicts Axillary Lymph Node Metastasis in Breast Cancer and Promotes Breast Cancer Cell Aggressiveness in vitro. Cell Physiol Biochem 2017;41:1072-1082.

13 Haque T, Nakada S, Hamdy RC: A review of FGF18: Its expression, signaling pathways and possible functions during embryogenesis and post-natal development. Histol Histopathol 2007;22:97-105.

14 Antoine M, Wirz W, Tag CG, Gressner AM, Wycislo M, Müller R, Kiefer P: Fibroblast growth factor 16 and 18 are expressed in human cardiovascular tissues and induce on endothelial cells migration but not proliferation. Biochem Biophys Res Commun 2006;346:224-233.

15 Liu Z, Lavine KJ, Hung IH, Ornitz DM: FGF18 is required for early chondrocyte proliferation, hypertrophy and vascular invasion of the growth plate. Dev Biol 2007;302:80-91.

-16 Franco-Montoya ML, Boucherat O, Thibault C, Chailley-Heu B, Incitti R, Delacourt C, Bourbon JR: Profiling target genes of FGF18 in the postnatal mouse lung: possible relevance for alveolar development. Physiol Genomics 2011;43:1226-1240.

17 Gauglhofer C, Sagmeister S, Schrottmaier W, Fischer C, Rodgarkia-Dara C, Mohr T, Stättner S, Bichler C: Upregulation of the fibroblast growth factor 8 subfamily in human hepatocellular carcinoma for cell survival and neoangiogenesis. Hepatology 2011;53:854-864.

18 Sonvilla G, Allerstorfer S, Stättner S, Karner J, Klimpfinger M, Fischer H, Grasl-Kraupp B, Holzmann K, Berger W, Wrba F, Marian B, Grusch M: FGF18 in colorectal tumour cells: autocrine and paracrine effects. Carcinogenesis 2008;29:15-24.

19 Ishibe T, Nakayama T, Okamoto T, Aoyama T, Nishijo K, Shibata KR, Shima Y, Nagayama S, Katagiri T, Nakamura Y, Nakamura T, Toguchida J: Disruption of fibroblast growth factor signal pathway inhibits the growth of synovial sarcomas: potential application of signal inhibitors to molecular target therapy. Clin Cancer Res 2005;11:2702-2712. 


\section{Cellular Physiology Cell Physiol Biochem 2018;49:1060-1073 and Biochemistry DOI: 10.1159/000493286 2018 2018 The Author(s). Published by S. Karger AG, Basel

20 Tchagang AB, Tewfik AH, DeRycke MS, Skubitz KM, Skubitz AP: Early detection of ovarian cancer using group biomarkers. Mol Cancer Ther 2008;7:27-37.

-21 Wei W, Mok SC, Oliva E, Kim SH, Mohapatra G, Birrer MJ: FGF18 as a prognostic and therapeutic biomarker in ovarian cancer. J Clin Invest 2013;123:4435-4448.

22 Wang H, Song C, Ding Y, Pan X, Ge Z, Tan BH, Gowda C, Sachdev M, Muthusami S, Ouyang H, Lai L, Francis OL, Morris CL, Abdel-Azim H, Dorsam G, Xiang M, Payne KJ, Dovat S: Transcriptional Regulation of JARID1B/ KDM5B Histone Demethylase by Ikaros, Histone Deacteylase 1 (HDAC1), and Casein Kinase 2 (CK2) in B Cell Acute Lymphoblastic Leukemia. J Biol Chem 2015;291:4004-4018.

23 Wang H, Song C, Gurel Z, Song N, Ma J, Ouyang H, Lai L, Payne KJ, Dovat S: Protein phosphatase 1 (PP1) and Casein Kinase II (CK2) regulate Ikaros-mediated repression of TdT in thymocytes and T-cell leukemia. Pediatr Blood Cancer 2014;61:2230-2235.

24 Rhodes DR, Yu J, Shanker K, Deshpande N, Varambally R, Ghosh D, Barrette T, Pandey A, Chinnaiyan AM: ONCOMINE: a cancer microarray database and integrated data-mining platform. Neoplasia 2004;6:1-6.

25 Anaya J: OncoLnc: linking TCGA survival data to mRNAs, miRNAs, and lncRNAs. Peer J Comp Sci 2016;2: e67.

26 Brown NS, Bicknell R: Hypoxia and oxidative stress in breast cancer. Oxidative stress: its effects on the growth, metastatic potential and response to therapy of breast cancer. Breast Cancer Res 2001;3:323-327.

27 An H, Stoops SL, Deane NG, Zhu J, Zi J, Weaver C, Waterson AG, Zijlstra A, Lindsley CW, Beauchamp RD: Small molecule/ML327 mediated transcriptional de-repression of E-cadherin and inhibition of epithelialto-mesenchymal transition. Oncotarget 2015;6:22934-22948.

28 Qin Y, Tang B, Hu CJ, Xiao YF, Xie R, Yong X, Wu YY, Dong H, Yang SM: An hTERT/ZEB1 complex directly regulates E-cadherin to promote epithelial-to-mesenchymal transition (EMT) in colorectal cancer. Oncotarget 2016;7:351-361.

-29 Jönsson JM, Johansson I, Dominguez-Valentin M, Kimbung S, Jönsson M, Bonde JH, Kannisto P, Måsbäck A, Malander S, Nilbert M, Hedenfalk I: Molecular subtyping of serous ovarian tumors reveals multiple connections to intrinsic breast cancer subtypes. PLoS One 2014;9:e107643.

-30 Davidson D, Blanc A, Filion D, Wang H, Plut P, Pfeffer G, Buschmann MD, Henderson JE: Fibroblast growth factor (FGF) 18 signals through FGF receptor 3 to promote chondrogenesis. J Biol Chem 2005;280:2050920515.

31 Kapadia RM, Guntur AR, Reinhold MI, Naski MC: Glycogen synthase kinase 3 controls endochondral bone development: contribution of fibroblast growth factor 18. Dev Biol 2005;285:496-507.

-32 Sonvilla G, Allerstorfer S, Heinzle C, Stättner S, Karner J, Klimpfinger M, Wrba F, Fischer H, Gauglhofer C, Spiegl-Kreinecker S, Grasl-Kraupp B, Holzmann K, Grusch M, Berger W, Marian B: Fibroblast growth factor receptor 3-IIIc mediates colorectal cancer growth and migration. Br J Cancer 2010;102:1145-1156.

33 Criscitiello C, Esposito A, De Placido S, Curigliano G: Targeting fibroblast growth factor receptor pathway in breast cancer. Curr Opin Oncol 2015;27:452-456.

-34 Shimokawa T, Furukawa Y, Sakai M, Li M, Miwa N, Lin YM, Nakamura Y: Involvement of the FGF18 gene in colorectal carcinogenesis, as a novel downstream target of the beta-catenin/T-cell factor complex. Cancer Res 2003;63:6116-6120.

35 Cobleigh MA, Shak S, Baker JB, Cronin MT: Gene expression markers for breast cancer prognosis. US Patent 2009; US7569345B2.

-36 Gotzmann J, Mikula M, Eger A, Schulte-Hermann R, Foisner R, Beug H, Mikulits W: Molecular aspects of epithelial cell plasticity: implications for local tumor invasion and metastasis. Mutat Res 2004;566:9-20.

-37 Chen L, Jingyu W, Jianlu K, Jinlong T, Yihua W, Enping X, Honghe Z, Maode L: GDF15 promotes EMT and metastasis in colorectal cancer. Oncotarget 2016;7:860-872.

-38 Lv ZD, Yang DX, Liu XP, Jin LY, Wang XG, Yang ZC, Liu D, Zhao JJ, Kong B, Li FN, Wang HB: MiR-212-5p Suppresses the Epithelial-Mesenchymal Transition in Triple-Negative Breast Cancer by Targeting Prrx2. Cell Physiol Biochem 2017;44:1785-1795.

39 Lv ZD, Wang HB, Liu XP, Jin LY, Shen RW, Wang XG, Kong B, Qu HL, Li FN, Yang QF: Silencing of Prrx2 Inhibits the Invasion and Metastasis of Breast Cancer both In vitro and In vivo by Reversing Epithelial-Mesenchymal Transition. Cell Physiol Biochem 2017;42:1847-1856.

40 Wang H, Deng X, Zhang J, Ou Z, Mai J, Ding S, Huo S: Elevated Expression of Zinc Finger Protein 703 Promotes Cell Proliferation and Metastasis through PI3K/AKT/GSK-3 $\beta$ Signalling in Oral Squamous Cell Carcinoma. Cell Physiol Biochem 2017;44:920-934. 


\section{Cellular Physiology Cell Physiol Biochem 2018;49:1060-1073}

and Biochemistry DOI: 10.1159/000493286 20102018 The Author(s). Published by S. Karger AG, Basel

Song et al.: FGF18 Promotes Migration and EMT in Breast Cancer

41 He F, Chen H, Yang P, Wu Q, Zhang T, Wang C, Wei J, Chen Z, Hu H, Li W, Cao J: Gankyrin sustains PI3K/GSK$3 \beta / \beta$-catenin signal activation and promotes colorectal cancer aggressiveness and progression. Oncotarget 2016;7:81156-81171.

42 Ding VW, Chen RH, McCormick F: Differential regulation of glycogen synthase kinase 3b by insulin and WNT signaling. J Bio Chem 2000;275:32475-32481.

-43 Behrens J, von Kries JP, Kühl M, Bruhn L, Wedlich D, Grosschedl R, Birchmeier W: Functional interaction of $\beta$-catenin with the transcription factor LEF-1. Nature 1996;382:638-642.

-44 Miller JR, Hocking AM, Brown JD, Moon RT: Mechanism and function of signal transduction by the Wnt/ $\beta$ catenin and Wnt/Ca ${ }^{2+}$ pathways. Oncogene 1999;18:7860-7872. 